UDK 352:614.8

https://doi.org/10.18485/fb_ic4hs.2018.14

\title{
LOCAL GOVERNMENTS' ENGAGEMENT IN INTEGRATING EMERGENCY AND ICT POLICYMAKING
}

\author{
Venelin TERZIEV*, Vesela RADOVIĆ $^{* *}$, Ekaterina ARABSKA ***
}

\begin{abstract}
The role of local authorities has been recognized as a base for improving human security and community wellbeing in the twenty-first century. This role can be enormously improved with the application of information and communication technologies (ICTs). Emergency management is a fundamental challenge for public administration in any country, particularly at the local level. The problems facing less developed countries, characterized by regional inequalities, are among the greatest challenges facing the world today and this issue is of paramount importance for human security and sustainable development. Local authorities have provided the foundation for the current focus on adequate emergency management in the affected territory. The main goal of the research presented here is to discuss how local authorities could improve the safety of citizens by creating a specific policy which is going to integrate the actions of emergency services and the use of ICTs at the same time. ICTs have the potential to raise local income and improve emergency response at the local level and human security. ICTs can enable a twoway communication between citizens and local authorities, potentially resulting in profound changes in local emergency management processes, as well as in the outcomes of social innovation processes. The methodology used in this article is standard for social research: appropriate data is examined in a comparative/historical analysis in this "desktop study". The results confirm that there has been a consistent institutional and political lag in local public administration, which has yet to recognize emergency management in the mainstream of its activities or use ICTs in an adequate scope in the process of enhancing human security in communities.
\end{abstract}

Keywords: local authority, emergency, ICTs, policy, sustainability

* Professor, PhD, Vasil Levski National Military University, Veliko Tarnovo, Bulgaria, E-mail: terziev@skmat.com

${ }^{* *} \mathrm{PhD}$, Institute for Multidisciplinary Research, University of Belgrade, Serbia, E-mail: vesela.radovic@imsi.rs

${ }^{* * *}$ Associate Professor, PhD, University of Agribusiness and Rural Development, Plovdiv, Bulgaria, Email: earabska@uard.bg 


\section{INTRODUCTION}

The September 2015 United Nations agenda, titled "Transforming our world: the 2030 Agenda for Sustainable Development" and echoing human security principles, emphasizes a "world free of poverty, hunger, disease and want ... free of fear and violence ... with equitable and universal access to quality education, health care and social protection ... to safe drinking water and sanitation ... where food is sufficient, safe, affordable and nutritious $\ldots$ where habits are safe, resilient and sustainable ... and where there is universal access to affordable, reliable and sustainable energy". This agenda contributed to the overdue recognition of the relationship between cities, sustainable development, socioeconomic factors, human settlement and natural resources. The world leaders' recognition of this relationship was materialized in the inclusion of Sustainable Development Goal (SDG) 11: "Make cities and human settlements inclusive, safe, resilient and sustainable" to strengthen resilience and the capacity to adapt to climate-related hazards and their impact on natural resources (United Nations, 2015). Furthermore, all 17 SGDs acknowledge the importance of the implementation of the adopted sustainable policy at the local level and the important role of local governments (Al-Zubi \& Radovic, 2018).

It is widely recognized that there is a dynamic and potentially mutually reinforcing relationship between emergencies (disasters) and development: emergencies impact on development and development impacts on emergencies (Keating et al., 2014). This is obvious at the national level, but even more visible at the local level. In many countries, the state of local self-management has deteriorated over the last few years. The state of the least developed municipalities in the Republic of Serbia is quite alarming. Human security is severely jeopardized in various emergencies. Many plans and projects for different improvement programs have been devised, yet positive results are slow to come (Radović \& Komatina-Petrovic, 2012; Radović, 2016).

The integration and use of information and communications technologies (ICTs) has enormous importance for emergency management at the local level. The role of ICTs is even more significant in the process of gaining access to information resources, which provide substantial benefits to emergency services. Therefore, the main objective of the current research is to review how ICT solutions can help local governments to communicate about existing risks, and hence about future sustainable development, increasing the awareness of the population and the mitigation of possible consequences for the affected population. The methodology used is related to the implementation of a "desktop study," document analysis, comparison, historical, etc. It allows the authors to review and analyze various documents from electronic databases, books, scholarly journals, official documents and positive practices from different countries.

The research also tackles the concepts of human security and environmental security as two concepts which intersect and overlap on the one hand, and diverge on the other. There are ongoing debates in the scientific community and the general public about what human security does or should mean so the authors have taken some account of the impact of environmental degradation on people and their communities, particularly in emergencies (Radovic, 2017). The results confirm that the need for creating a coherent emergency management policy for managing existing risks at the local level, which includes the deployment of ICTs, is a significant challenge. 


\section{EMBRACING ICTS IN THE PROCESS OF EMERGENCY MANAGEMENT AT THE LOCAL LEVEL}

The emergency management system (EMS) is a structure for the coordination between the government, local emergency response organizations and other interested parties. It provides and facilitates the flow of emergency information and resources within and between the organizational levels of field response, local government, operational areas, regions and state management (Cao et al., 2018). The existing gap related to emergency management at the local level is noted in the Serbian national progress report on the implementation of the 2013-2015 Hyogo Framework for Action (Ministry of Interior, 2015). In this report, furthermore, the core indicator 3, related to priority of action 1 , shows that specific legislation for the local level with a mandate for disaster risk reduction (DRR) exists in Serbia, but without a regular allocation for DRR to local governments. The same goes for the core indicator for priority of action 2 and 3, which states that achievements are neither comprehensive nor substantial despite the institutional commitment. Despite some positive actions (training of the local government, disaster management and preventive risk management, etc.), the most important actions are missing - e.g. guidance for risk reduction and availability of information on DRR practices at all community levels (Ministry of Interior, 2015: 27).

ICTs are an urgent need in the work of emergency services because the most important step towards reducing risks in community is to analyze the potential risks and identify measures that can prevent, mitigate or prepare for emergencies. Hence, local governments should be able to recognize the risks to which their communities are exposed. They must be actively involved in the design and maintenance of early warning systems and understand the relayed information in order to be able to advise, instruct or engage the local population in a manner that increases the safety and reduces the potential losses (Vujic et al., 2013). At the local level the use of ICT solutions for improving human security has to be promoted more efficiently. In this way, all stakeholders could contribute enormously to the extent to which community security, as one of the elements of human security, is being advanced through the security discourses and practices in emergency management.

David Kobia has said that "web programming helps communities facing catastrophe around the world". His creation, Ushaidi, is recognized by Ethan Zuckerman as one of the most globally significant technology projects. It has helped first responders, including members of the U.S. military, who used Ushaidi's map to set priorities, organize and reach distressed people in the aftermath of the Haiti earthquake in 2010 (Greenwald, 2010).

\section{ICTS AS A DRIVER FOR MAXIMIZING COMMUNITY SECURITY IN EMERGENCIES}

Local governments are faced with exciting challenges and opportunities in the twenty-first century. Their main activities are connected to compiling and assessing data and information on the current and foreseeable state of risks. These include an increased scientific understanding of hazards and societal responses, as well as revolutionary 
technologies. The power of social ICTs is becoming enormous (in the media as well). In this area, social capital is the invincible link that inspires trust during mandatory evacuation, volunteers to participate in an exercise, donors for safety programs and support for critical infrastructure implementation. If social capital continues to grow via online connection, it is highly likely that there will be a further transformation in emergency management (For-mukwai 2012: 4).

In this process, it is necessary to mention the existence of the digital divide. This problem is often discussed in an international context, indicating that certain countries are far better equipped than other, less developed countries to exploit the benefits of rapidly expanding ICTs. This issue is visible if we consider regional inequalities in Serbia. At the local level, the proposed ICT frameworks are based on the communication and collaboration difficulties experienced during events in recent history as well as on the recommendations put forward by authorities from developed countries in their reports. In practice, the Intelligent Disaster Collaboration System (IDCS) model developed to improve collaboration patterns and the information flow during the emergency management process in the United Kingdom has proved to be very successful (Sagun et al., 2009).

In her first talk in the Serbian Parliament, Serbian Prime Minister Ana Brnabić stated: "Now is the moment to take a step further and to transfer our society, state and economy into the $21^{\text {st }}$ century, which is marked by digitalisation. Digitalisation is an in-depth transformation of the manner in which we produce, spend, learn, work and exchange (Brnabić, 2017)." Hence, we have to embrace digitalization in the area of emergency management and understand how ICT can be more useful in the process of increasing human security. In the Republic of Serbia, where the ICT framework is not fully established, local governments have to bear in mind the advantages and deficiencies of different ICT frameworks in coordinated actions with competent authorities. Each time that communication networks services, considered as an important part of critical infrastructure, are unavailable when disasters strike, this creates evident societal problems for people who are desperately seeking for information or trying to communicate with each other. The COST Action CA15127 states: Resilient communication services protecting end-user applications from disaster-based failures (RECODIS) has tried to fill this gap by offering the respective solutions to provide resilient communications in the presence of disaster-based disruptions of all types for existing communication networks (e.g. IPv4-based, current Internet), as well as emerging architectures of the global communications infrastructure (i.e. the Future Internet) (European Union, 2018).

\section{CONCLUSION}

Disaster-based disruptions which seriously degrade the performance of any communication network (resulting from natural disasters, technology-related disasters or malicious attacks) are now gaining importance due to the observed increase of their intensity and scale. Experts therefore propose more advanced ICT frameworks with a focus on automated, intelligent or self-healing ICT systems and on interoperability and information security during an emergency. Local governments have to develop and implement more effective emergency management solutions, closely linked with other 
local public policies, which rely on sophisticated mutual aid networks, ICTs and partnerships, not only among first responders but also throughout all functions of stakeholders in a community. Hence, this action has to be involved in all kinds of local policies, in which the use of ICTs has to become an unavoidable precondition. Serbian policymakers have to be more aware of their leading role in creating new opportunities and redefined the emergency system at all levels due to digitalisation.

\section{ACKNOWLEDGEMENT}

This article is a part of research related with ongoing COST Action CA15127: Resilient communication services protecting end-user applications from disaster-based failures (RECODIS).

\section{REFERENCES}

Al-Zubi, M., \& Radovic, V. (2018). Sustainable Cities and Communities: Towards inclusive, safe, and resilient settlements. Emerald Publishing Limited.

Cao J., Zhu L., Han H., Zhu X. (2018) Overview of Emergency Management. In: Modern Emergency Management. Springer, Singapore.

European Union. COST Action CA15127. (2018, August 30). Resilient communication services protecting end-user applications from disaster-based failures (RECODIS). Retrieved from: http://www.cost.eu/COST_Actions/ca/CA15127. Accessed: 13.09.2018.

For-mukwai, G.F. (2012). The Transformative Power of Social Media on Emergency and Crises Management. In: Murrey, J. Managing Crises and Disasers with Emergining Techologies. IGI Global, Hershey, Pensylvania, USA.

Greenwald, T. (2010). David Koba about Ushahidi. Techology Review, 46-47.

Keating, A., Campbell, K., Mechler, R., Michel-Kerjan, E., Mochizuki, J., Kunreuther, H., Bayer, J., Hanger, S., McCallum, I., See, L., Williges, K., Atreya, A., Botzen, W., Collier, B., Czajkowski, J., Hochrainer, S., \& Egan, C. (2014). Operationalizing Resilience against Natural Disaster Risk: Opportunities, Barriers, and a Way Forward. Zurich Flood Resilience Alliance. Retrieved from: http://opim.wharton.upenn.edu/risk/library/zurichfloodresiliencealliance_Resilien ceWhitePaper_2014.pdf. Accessed: 13.09.2018.

Ministry of Interior. Serbia National progress report on the Implementation of the Hyogo Framework for Action (2013-2015). Retrieved from: http://www.preventionweb.net/english/hyogo/progress/reports/. Accessed: 13.09.2018.

Radovic, V., (2016). Mitigation Efforts in Rural Communities after Extreme weather Events- New Insights for Stakeholders. Journal of Innovations and Sustainability, 2 (3): 37-56.

Radovic, V. (2017). Corporate Sustainability and Responsibility and Disaster Risk Reduction: A Serbian Overview. Book CSR 2.0 and the New Era of Corporate Citizenship, Chapter 8, Ed.: Camilleri, M. IGI Global, 147-164. 
Radovic, V., \& Komatina-Petrović, S. (2012). From failure to success: Serbian approach in mitigation of global climate change and extreme weather events., Journal of Environmental Protection and Ecology, 4 (13): 2207-2214.

Sagun, A., Bouchlaghem, D., \& Anumba, Ch. J. (2009). A scenario-based study on information flow and collaboration patterns in disaster management. Disasters 33 (2): 214-238.

United Nations. (2015). Transforming our world: The 2030 Agenda for sustainable development. United Nations. New York.

Vujić, B., Radovic, V., \& Lečić, D. (2013). Application of ICT as a necessary tool of emergency response in urban areas. University of Novi Sad, Faculty of Technical Sciences "Mihajlo Pupin" International Conference Ecology in urban areas, Zrenjanin, 518-524.

National Assembly of the Republic of Serbia. 28 June 2017 KEYNOTE ADDRESS BY SERBIAN PRIME MINISTER DESIGNATE ANA BRNABIĆ. Available on: http://www.parlament.rs/upload/documents/activities/28.06.2017.\%20KEYNOTE \%20ADDRESS\%20BY\%20SERBIAN\%20PM\%20DESIGNATE\%20ANA\%20B RNABIC.pdf 